\title{
POSITIVE EFFECT OF LEARNING FOREIGN LANGUAGE IN A HEALTHY ELDERLY
}

\author{
Ahmad Muhammad Diponegoro \\ Ahmad Dahlan University of Jogjakarta
}

\begin{abstract}
The study of elderly found that almost all cognitive functions decline with age. Results of previous studies have shown that cognitive training related to everyday life (reading aloud and learning vocabularies and wisdom), namely learning intervention or therapy, can improve two cognitive function (executive functions and processing speed) in elderly people. This study investigates the positive effects of learning foreign language on cognitive functions of an elderly person. This study provides sufficient evidence of learning foreign language effectiveness in a healthy elderly. Method used is one single case subject design. A healthy elderly was asked to read aloud and memorize several Quran chapters and verses and write Arabic verbs proposition and several nouns found it the memorized verses and put it into correct sentences. The written words are concerning daily life activity. Since the Qur'an has best structure of Arab sentence, memorizing it help to understand the Arabic sentences properly. The finding support the previous research that the elderly able to improve their cognitive processes and ability through studying foreign language.
\end{abstract}

Keywords: Psycholinguistic, foreign language, cognitive function, reading

On a typical Saturday, French, Italian, Arabic and Mandarin echo through the classrooms at the University of British Columbia. These are not only the usual twenty-something subjects, but boisterous mature learners. "When they see all the white-haired people in the class, they go, oh dear, do I have to study with them?" said Nan Hornaas, 74. "But I think we've reached that period where we're in our second childhood, and we act younger than they do."

Every Saturday morning for most of the year, In the different place not far away from the first, the Vancouver campus is packed with senior citizens learning new languages through the demand for language courses among seniors has grown in recent years, said Nina Parr, Program Director of Languages, Culture and Travel at Continuing Studies.

The department will likely continue to ex- pand its programming for its more elderly subjects in the coming years. The non-credit courses are open to all ages, but senior citizens make up most of the language subjects. In an Advanced French class, subjects range from age 27 to 82 . A group of seniors in the class have been attending together for up to 20 years.

People found in the northern part of Yogyakarta Indonesia every Monday evening for most of the year, In the different place little bit far away from the first and second place, Taruna al-Qur'an institution one of the institution that accept elderly in Yogyakarta Indonesia is also packed with senior citizens learning new language: Arabic language. In arabic class, subjects approximately range from age 60 to 70 . A group of seniors in the Arabic class have been attending together for up to 10 years. They are not only studying 
Arabic, but also Qur'an and Sunnah.

Arabic is spoken throughout the Arabian Peninsula, Iraq, Syria, Jordan, Lebanon, Palestine, Morocco, Tunisia, Algeria, Libya, Egypt, Sudan, Mauritania, and Chad. It is the mother tongue of over 225 million people in Africa and Asia. Since the Qur'an is written in Arabic, people in other Muslim countries have at least some basic knowledge of Arabic like in Indonesia (largest Muslim population), Malaysia, Pakistan, Bangladesh, and Turkey.

Arabic has 28 consonantal phonemes (including two semi-vowels). Arabic is different than English when it comes to the way it's written (right to left) and some sounds don't exist in English like the glottal stop, usually transliterated by (') like in the word 'elm (science). Also the consonants (q) and (gh) are the sounds produced the farthest back in the mouth in English (called 'velars' because the tongue touches the soft palate or velum), like in qalam (pen), and loghah (language). (kh) which sounds like the Scottish ch as in (Loch Ness lake).

Like many other languages, Arabic has a different grammar than English. That doesn't make it hard, only distinctive. Some grammatical rules are easier than the ones existing in English. Scientists need psycholinguistics or psychology of language in order to understand this phenomenon comprehensively.

Psycholinguistics or psychology of language is the study of the psychological and neurobiological factors that enable humans to acquire, use, comprehend and produce language. According to David W. Carroll (2008) Psycholinguistics is part of the emerging field of study called cognitive science. The psychological study of language is called psycholinguistics. It is an interdisciplinary venture that draws upon the insights of psychologists, linguists, computer scientists, neuroscientists, and philosophers to study the mind and mental process. Some of the topics that have been studied by cognitive scientists include problem solving, memory, imagery, and lan- guage.

Normally, Qurán studies begin by the learning of the Arabic letters and the alphabet. Sentences and verses are then memorized, and if the pupil is able to quote the verses he may try to write them on his papers and then to read them. In addition to the content of the Koran, the pupils are taught the five pillars of Islam, since they are expected to start praying (Daun, 1992)

Young children generally acquire a second language through large amounts of exposure to the new language. In contrast, second-language learning in adults appears to be most efficient when they adopt explicit strategies for the language and when they are more responsive to feedback than children. As a result, adults often learn a second language at a faster pace than young children. Indeed, that the higher the level of competence in the second language, the more likely that the same cortex areas will be activated. So the older second-language learner may find acquisition of new vocabulary easier than acquiring new sounds or new grammar (Bengtson, V.L, 2009).

Almost all cognitive functions decline with age. Results of previous studies have shown that cognitive training related to everyday life (reading aloud and learning vocabularies and wisdom), namely learning intervention or therapy, can improve two cognitive function (executive functions and processing speed) in elderly people.

However, it remains unclear whether learning intervention or therapy engenders improvement of various cognitive functions or not. We investigate the impact of learning intervention or therapy on various cognitive functions (executive functions, episodic memory, short-term memory, working memory, attention, reading ability, and processing speed) in healthy older adults.

This study investigates the effects of learning foreign language (Arabic) on cognitive functions of an elderly person. This study 
provides sufficient evidence of learning foreign language effectiveness. Most cognitive functions, which are correlated strongly with daily life activities, decrease with age. These study results can elucidate effects of cognitive training on elderly people.

Cognitive function changes during a person's lifetime (Sossin, W.S, 2008). It has been observed that some cognitive functions such as those involving crystallized knowledge (e.g., vocabulary) remain preserved or even improve with age (Schaie, K., Warner and Carstensen, 2006). C. G. Kruse (2006) explained that normal older persons and even those with mild cognitive deficits can benefit from cognitive training. People who reach old age with greater stores of knowledge may show increased adaptivity Some cognitive functions, such as vocabulary, improve with age (Kruse, C.G., 2006).

Mental ability does not decline along with physical vigor (Frolik, 1999). Researchers have been able to reverse the supposedly normal intellectual declines of 60 -to 80 year-olds by tutoring them in problem solving. Reaction time, intellectual speed and efficiency, nonverbal intelligence, and maximum work rate for short periods may diminish by age 75 . However, understanding vocabulary, ability to remember key information, and verbal intelligence remain about the same (Smart, 2012).

Recalling information takes longer. As individuals reach their mid-to late sixties, the brain slows down, but usually just by a matter of milliseconds. Older adults eventually adapt and perform just as well as younger ones. 2. Distractions become more disruptive. Subjects can study and listen to the qur'an at the same time. But older individuals find it much more difficult to divide their attention or to remember details after having switched their attention to something else. 3. Learning new information is harder. The quality of memory doesn't change, just the speed at which they receive, absorb, and reach to in- formation. That's why strategies like taking notes or outlining material become critical for older subjects, especially when learning new skills, however, adding to existing knowledge remains as easy as ever (Hales, 2008). In any memory test involving knowledge of the world, vocabulary, or judgment, elder people outperform their younger counterparts (Lewis, 2003).

Decline in cognitive ability engenders/ produce difficulty in performing basic daily living activities. Consequently, maintaining or improving cognitive function in older adults is drawing increasing attention (Stewart, 2005: 180)

Although human cognitive function typically declines with age, earlier studies showed that several cognitive training programs can improve cognitive functions such as memory (Abou-Saleh, 2011: 398), processing speed (Attix, and Welsh-Bohmer, 2006: 264), executive function, and attention in healthy elderly people (Woo and Keatinge, 2008: 383).

It is particularly interesting that some studies have demonstrated that the effects of cognitive training can impact non-trained cognitive functions or tasks (Ravdin, 2012:179). For instance, Lalitha assessed several facets of memory viz; working memory, long term memory in the elderly, and their relationship to psychological and personal variables. Age, gender, education, and other demographic factors were related to memory status among the aged. Of them ,the level of formal education was found to be an important correlate of various facets of memory in the elderly (Wisocki, 1991: 24).

Schmiedek conducted a working memory training study for elderly people in which participants were required to perform auditory recognition, discrimination, and memory tasks for about 15 min per day at least 5 days per week, for 8 to 10 weeks. Elderly people in the training group showed improvement of cognitive function in directly trained tasks (for example, alpha span and word list) and 
in cognitive functions in non-trained tasks (for example, animal span, rotation span, word pairs). Results of earlier studies show that cognitive training (for example working memory training) can improve cognitive functions in elderly people.

In line with previous studies using cognitive training for elderly people, Nouchi (2012) recently developed a new mode of cognitive training using reading aloud, and solving of simple arithmetic calculations,. This cognitive training is designed for stimulation of the frontal cortex (especially dorsolateral prefrontal cortex) and of the temporal and parietal association cortices by cognitive tasks, thereby engendering improvement of the function of these cortices

In this research In line with previous studies using cognitive training for elderly people, we recently developed a new mode of cognitive training using reading aloud of qur'anic verses, writing Arabic verbs, nouns and proposition (tasrif, and I'rab) and solving of simple grammatical problems. This cognitive training is designed for stimulation of the frontal cortex (especially dorsolateral prefrontal cortex) and of the temporal and parietal association cortices by cognitive tasks, thereby engendering improvement of the function of these cortices

Previous studies using learning intervention or therapy have demonstrated that learning intervention or therapy can improve executive functions and processing speed in healthy elderly people. For instance, Sarah A. Raskin (2011) described A total of 2,832 older adults were divided into one of four training groups (memory training, reasoning training, speed processing training, and nonactive control) the memory and reasoning training involved teaching of cognitive strategies, and were not therefore primarily restorative in nature ... but the speed-of-processing training involved repeated practice on tasks that required visual search and divided attention. Eighty-nine percent of participants were able to complete the treatment, and each training procedure produced significant imvrovement in the trained cognitive ability, which was retained across 5 years of follow-up testing. All three training groups reported improvements in their ability to handle day-to-day tasks, and the speed-of-processing group showed improvement on a performance based measure of daily functioning. The sentences of each listening span test were read by one of the researchers one at a time and participants had to ... of the texts, the subject was asked to write down everything he could remember about the text just read / or listened to functions in elderly people.

\section{METHOD}

This study, which was registered in the University of Ahmad Dahlan the faculty of psychology, a single case design conducted in Yogyakarta city, Indonesia. To see the impact of cognitive training on cognitive functions in healthy elderly person, we use an intervention. Participant is recruited from Kraton district the general population through an invitation

The purpose of this intervention is to investigate transfer effects of cognitive intervention of cognitive function in a healthy older adult. The criteria include participant who report themselves to be right-handed, native Indonesian speaker, unconcerned about their own memory functions, not using medications known to interfere with cognitive functions (including benzodiazepines, antidepressants or other central nervous agents), and having no disease known to affect the central nervous system, including thyroid disease, multiple sclerosis, Parkinson disease, stroke, severe hypertension, and diabetes. Age of participant is over 65 years old.

\section{Dialog memorization}

Dialogs or short conversations of simple Arabic words found in the verses between subject and experimenter used to begin a new lesson. Subject memorizes the dialog through 
mimicry; subject takes the role of one person in the dialog, and the experimenter the other. After the subject has learned the one person's lines, they switch roles and memorize the other person's part.

\section{Backward build-up (expansion) drill}

This drill is used when a long line for a dialog is giving subject trouble, for example surah Yaasiiin, Munaafiqun and Jum'ah. The experimenter breaks down the line into several parts. The subject repeats a part of the sentence. Then, following the experimenter's cue, the subject expands what he is repeating part by part until they are able to repeat the entire line. This also directs more subject attention to the end of the sentence, where new information typically occurs. Repletion drill: subjects are asked to repeat the experimenter's model as accurately and as quickly as possible. This drill is often used to teach the lines of the dialog.

\section{Single-slot substitution drill}

The experimenter says a line, usually from the dialog. Next, the experimenter says a word or a phrase-called the cue. The subjects repeat the line the experimenter has given them, substituting the cue into the line in its proper place. The major purpose of this drill is to give the subjects practice in finding and filling in the slots of a sentence.

Transformation drill

The experimenter gives subject a certain kind of sentence pattern, an affirmative sentence for example. Subjects are asked to transform this sentence into a negative sentence. Other examples of transformations to ask of subjects are changing a statement into a question, an active sentence into a passive one, or direct speech into reported speech.

\section{Question - and - answer drill}

This drill gives subjects practice with answering questions. The subjects should answer the experimenter's questions.

Complete the dialog.
Selected words are erased from a dialog subjects have learned. Subjects complete the dialog by filling the blanks with the missing words. The experimenter tells the subjects they must change the form of the verb from first person singular to third person singular verbs in the present tense in Arabic. He then gives the subject a list of verbs and ask him to change the verbs into the third person singular and plural in the past and present tense form.

\section{Discussion}

The cognitive intervention method is similar as that used in our previous study using learning intervention or therapy to increase memorization for healthy older adults. Training tasks use two simple tasks (solving Arabic grammatical problems and memorizing chapters in Qur'an). We prepared various materials used in everyday classes of qur'anic studies in pesantren for the elderly and mosques.. The reading texts are found in the holy qur'an and the Arabic lesson from Gontor Ponorogo. For the Arabic language problems, the lowest level of difficulty is reading and writing simple sentences.

One or two weeks before the start of the intervention program, the subject is asked to prepare the material with the help of experimenter. The appropriate level of difficulty and workload for participant is assessed by tests, which consist of several verbs and proposition found in Qur'an.. The language problems range in difficulty from reading and comprehending Arabic verbs quranic surah, or verses (17 words) to reading and comprehending and memorizing surah (110 characters). For tests of both types, the percentage of correct answers and the time it takes to solve all problems are determined. In this intervention, the difficulty level and workload of each task are set such that participant is able to solve the problems with ease and without mental stress within $15 \mathrm{~min}$.

The cognitive intervention is scheduled 
to be conducted for 23 weeks. The subject is asked to go to the special place in Yogyakarta once a week. They are instructed to complete at least one sheets of each task prepared for each for that day, which are assessed by experimenter. Mistakes are corrected by the experimenter. The study period ends when the participants complete each of the problems correctly. The daily learning time for the two tasks is approximately $30 \mathrm{~min}$. The cognitive intervention is undertaken on an individual basis, so that the participant can decide how to use his learning time of 15 min freely. Participant are also asked to do his homework. Regarding his homework, participant is asked to complete at least two sheets of each task prepared for each. Furthermore, participant is asked to bring back their achievements of homework on the next studying day. The experimenter checks their homework and provides advice when necessary.

To evaluate the beneficial effects of learning intervention or therapy on cognitive functions, we evaluate a broad range of cognitive functions. Evaluations of the cognitive functions are divisible into seven categories (memory, reading ability, attention, and processing speed). Executive functions are evaluated using the Krapyak test and verbal fluency task. Memory is evaluated using logical memory and Reading ability is evaluated using the Quranic reading test. Attention is evaluated using the digit cancellation task

We evaluate this cognitive function before and after the intervention period (6 months). We selected ST as the primary outcome measure because: (1) learning intervention or therapy is expected to improve executive functions, and a previous study showed learning intervention or therapy can improve executive function

Verbal fluency task measures executive function. We use the arabic version of VFT, which has two tasks (letter fluency task (LFT) and category fluency (CFT) task. In LFT, a Arabic word, ' $k a d z a b a$ ', is given to participant, who is then asked to generate all the verb forms beginning with this word-. In CFT, a category name (part of the body) is given to participant, who is then asked to generate many words of a certain category (part of the body). The participant is instructed not to repeat one that has already been stated.

Logical memory (LM) evaluates the performance of episodic memory. LM consists of two short paragraph-length chapters (Chapter Munafiqun and Chapter Jum'ah). In LM, participant must memorize the chapter. The chapters are scored in terms of the number of story units recalled, The primary measure for this task is the number of correct story units recalled. The Arabic reading test measures reading ability. The reading stimuli are printed out randomly for reading. The participants are asked to read each Arabic letter compound word aloud. The primary measure for this task is the number of correct items.

\section{DISCUSSION}

This study is designed to investigate the positive effects of learning intervention or therapy on cognitive function such memory, , reading ability, and attention in a healthy elderly people. It has several strengths compared to earlier studies using cognitive training for elderly people. First, this study was designed according to Islamic teaching which are intended to improve quality of learning in moslem elderly Consequently, this study has been structured to enable its reproduction in both research and clinical settings. Moreover, we can provide sufficient evidence of the effectiveness of cognitive training such as learning intervention or therapy.

Various cognitive functions are necessary to support our actions and behaviors in everyday life. For instance, when we read qur'an and teach to the public after praying, he must: (1) choose a surah (executive functions); (2) remember the surah contents (memory); (3) seek and select proper advices from surah (attention); and (4) arrange and deliver and 
prepare the best materials that match the situations with speed and efficiency (processing speed). Because of the complexity of such an apparently simple task, it is expected to be important to investigate the positive effects of learning intervention or therapy on widely various cognitive functions.

Third, we use simple, easily learned training tasks (reading aloud and simple grammar) using paper and pen. Most training tasks in previous studies were complex tasks using computers (Czaja, 1993: 59-67). Using computers might make it easy to record data precisely and to control tasks. Nevertheless, elderly people often have difficulty using computers (Sharit, 1994:559-577). The difficulty using computers might cause frustration and other negative emotion, possibly reducing their motivation to continue. This training tasks are more familiar to elderly people and thus expected to encourage their willingness to study Quran and Arabic language.

This study has some limitations. A first limitation is the intervention period. Our intervention period is not recorded properly. Some previous studies have shown that short-term intervention (four example 4 to 6

\section{REFERENCES}

Abou-Saleh, Mohammed T. (2001). Principles and Practice of Geriatric Psychiatry. Oxford: Wiley-Blackwell.

Attix, Deborah K., and Kathleen A. Welsh-Bohmer. (2006). Geriatric Neuropsychology: Assessment and Intervention. New York, N.Y. [u.a.]: Guilford Press.

Ball K, Berch DB, Helmers KF, Jobe JB, Leveck MD, Marsiske M, Morris JN, Rebok GW, Smith DM, Tennstedt SL, et al. (2002). Effects of cognitive training interventions with older adults: a randomized controlled trial. JAMA, 288:2271-2281.

Bengtson, Vern L. (2009). Handbook of Theories of Aging. New York: Springer, weeks) improved cognitive function in elderly people (Ball K, 2002: 2271-2281). Considering reduced costs for elderly people, shorter intervention studies using learning intervention or therapy would be also needed. A second limitation is participant. We recruit only one healthy elderly people for participation in this study. Providing the validity of effects of learning intervention or therapy on widely various cognitive functions, we must conduct the same randomized controlled trial (RCT) for non-healthy elderly people such as those with dementia or depression.

\section{CONCLUSION}

In summary, this study is the first to reveal the positive effects of learning intervention on a wide range of cognitive functions in elderly people. This study is designed to provide sufficient evidence of effectiveness of learning intervention or therapy. Given that most cognitive functions decrease with age (Hedden $\mathrm{T}, 2004:$ 87-96.) and that these functions are strongly correlated with daily life activities (Cahn-Weiner DA, 2000: 187-195), the results can elucidate the effects of cognitive training for elderly people.

Bissig D, Lustig C. (2007). Who benefits from memory training? Psychology Science, (18), 720-726.

Cahn-Weiner DA, Malloy PF, Boyle PA, Marran M, Salloway S. (2000). Prediction of functional status from neuropsychological tests in community-dwelling elderly individuals. Clin Neuropsychology (14),187-195.

Czaja SJ, Sharit J (1993). Age differences in the performance of computer-based work. Psychology Aging, (8),59-67.

Daun, Holger. (1992). Childhood Learning and Adult Life: The Functions of Indigenous, Islamic and Western Education in an African Context. Stockholm: Institute of 
International Education.

Frolik, Lawrence A. Aging and the Law (1999). An Interdisciplinary Reader. Philadelphia, PA: Temple University Press.

Hales, Dianne R (2008). An Invitation to Health. Australia: Thomson/Wadsworth.

Hales, Dianne R. (2011). An Invitation to Health: Choosing to Change.

Hedden T, Gabrieli JD (2004). Insights into the ageing mind: a view from cognitive neuroscience. Nat Rev Neuroscience, (5), 87-96.

Hof, Patrick R., and Charles V. Mobbs (2001). Functional Neurobiology of Aging. San Diego, CA: Academic Press.

Kruse, C. G (2006). Thinking About Cognition: Concepts, Targets, and Therapeutics. Amsterdam: IOS Press.

Ravdin, Lisa, and Katzen, Heather (2012). Clinical Handbook on the Neuropsychology of Aging and Dementia. Springer Verlag.

Schaie, K. Warner, and Laura L. Carstensen (2006). Social Structures, Aging, and Self-Regulation in the Elderly. New
York: Springer.

Sharit J, Czaja SJ (1994). Ageing, computerbased task performance, and stress: issues and challenges. Ergonomics (37), 559-577.

Smart, Julie (2012). Disability Across the Developmental Life Span: For the Rehabilitation Counselor. New York, NY: Springer.

Sossin, Wayne S (2008). Essence of Memory. Amsterdam [etc.]: Elsevier, p. 366.

Stewart, Donna E (2005). Menopause A Mental Health Practitioner's Guide. Washington, DC: American Psychiatric Pub.

Wisocki, Patricia A. (1991). Handbook of Clinical Behavior Intervention or therapy with the Elderly Client. New York: Plenum Press.

Woo, Stephanie M., and Carolyn Keatinge (2008). Diagnosis and Treatment of Mental Disorders Across the Lifespan. Hoboken, N.J.: John Wiley \& Sons.

Zaun, Kathy, and Lisa Marty (2002). Inside Islam. St. Louis, Mo: Milliken Pub. Co. 